Reprod. Nutr. Dévelop., 1988, 28 (1), 173-174.

\title{
Influences comparées du foin de luzerne et de l'ensilage de maïs sur la dégradabilité in sacco des constituants d'aliments concentrés riches en céréales ou en sous-produits à paroi très digestible
}

\author{
S. HAKIM, D. SAUVANT, Sylvie GIGER, P. CHAPOUTOT
}

Station de Nutrition et Alimentation (I.N.R.A.) de I'I.N.A.-PG. 16, rue Cl. Bernard, 75231 Paris Cedex 05.

Summary. Two groups of compound feeds one riche in cereal products and the other rich in by-products with highly digestible fiber, were studied in sacco with diets based on lucerne hay (FL) or maize silage (EM). MS depressed the in sacco degradability of dry matter, nitrogen and particularly cell wall constituants after 12 and $24 \mathrm{~h}$ of incubation.

Des aliments concentrés composés de même digestibilité peuvent être constitués d'une majorité de produits céréaliers ou de sous-produits agroindustriels à paroi très digestible (Sauvant, 1980). L'objet de l'étude est d'évaluer l'influence de la nature du fourrage sur la dégradation ruminale des constituants de ces deux types de concentrés.

Matériel et méthodes. L'étude a été conduite sur chèvres alpines sèches porteuses de canules de rumen. La ration, ingérée à un niveau situé entre 40 et $55 \mathrm{~g}$ de matière sèche (MS) par kgPV0,75, était constituée de foin de luzerne ( $F L$ ) pour 5 chèvres, ou d'ensilage de maïs (EM) pour 4 chèvres. Ils étaient complémentés par un aliment concentré représentant de 25 à $30 \%$ de la MS ingérée. Les teneurs moyennes en matières azotées sont de 17,5 et $12 \%$ de la MS et la digestibilité calculée de la matière organique de 67 et $77 \%$ pour les régimes $\mathrm{FL}$ et $\mathrm{EM}$ respectivement.

La dégradation ruminale in sacco des aliments concentrés a été mesurée à raison de 3 répétitions par aliment selon la méthode décrite par Gueneau et Bertrand (1984) ; les sacs ont été retirés après $6,12,24$ et 48 h d'incubation. Les 10 mélanges concentrés étudiés correspondent à deux groupes de 5 : les aliments A sont caractérisés par une teneur maximisée en céréales et issues (62 à $81 \%$ ) et les aliments $P$ par des matières premières riches en paroi très digestible $(50$ à $80 \%)$ : pulpes de betteraves et d'agrumes, pellicules de soja, lupin, tourteau de palmiste. Les aliments $A$ présentent des teneurs moyennes en matières azotées, cellulose brute, parois totales (NDF), lignocellulose (ADF) et lignine au détergent acide (Li) de $18,5,7,1,18,3,7,1$ et $1,6 \%$ de la MS. Les aliments $P$ présentent des teneurs moyennes pour les mêmes caractéristiques analytiques de 19,6, 15,3, $33,4,19,3$ et $1,9 \%$ de la MS respectivement. Les aliments $A$ et $P$ présentent en moyenne la même valeur de digestibilité mesurée in vivo de la matière organique (82,1 et $82,6 \%$ pour les aliments $A$ et $P$ respectivement).

L'analyse statistique est effectuée séparément aux 4 temps d'incubation selon un dispositif en split-splot ; la première résiduelle (inter-aliment concentré, intra-type de concentré) sert à tester l'influence de la nature du concentré, la seconde (interaction inter-concentré $x$ fourrage) l'influence de la nature du fourrage et de l'interaction fourrage concentré.

Reproduction, Nutrition, Développement, $n^{\circ} 1-88 .-12$ 
Résultats et discussion. Avec le régime FL la dégradation des aliments est significativement supérieure aux temps 12 et $24 \mathrm{~h}$ pour la MS, l'azote et surtout des fractions NDF et ADF (tabl. 1); à $48 \mathrm{~h}$ un effet significatif persiste uniquement pour le NDF. Une interaction significative apparaît entre les types de fourrage et de concentré pour la dégradation à 6 et $12 \mathrm{~h}$ de la MS soluble dans le détergent neutre : celle-ci est plus dégradée avec FL pour l'aliment $P$, alors que l'inverse se produit pour l'aliment $A$; cette interaction se répercute en partie sur la dégradabilité de la MS à 12h. Les deux types d'aliment concentré diffèrent largement par le niveau et la vitesse de dégradation de leurs constituants pariétaux. Des études ont déjà montré l'influence des variations du rapport fourrage/concentré sur la dégradabilité in sacco de la MS des aliments (Lindberg, 1981 ; Weakley et al., 1983). Ce travail indique que la nature du fourrage inclus dans une ration mixte présente également une influence significative. L'ensilage de maïs a principalement réduit l'activité cellulolytique, conséquence vraisemblable de son plus faible niveau d'apport d'azote fermentescible et des valeurs inférieures du $\mathrm{pH}$ ruminal.

La méthode utilisée peut être préconisée pour quantifier les phénomènes d'interaction digestive dans le réticulo-rumen.

TABL. 1. - Dégradabilité in sacco des constituants des aliments : Influences du régime alimentaire (foin de luzerne, FL ou ensilage de maïs, EM) et différences entre les aliments riches en sous-produits à paroi très digestible $(\mathrm{P})$ ou en produits céréaliers.

\begin{tabular}{|c|c|c|c|c|c|c|c|c|c|}
\hline \multirow{3}{*}{ Caractéristiques } & \multirow[b]{3}{*}{ (1) } & \multicolumn{8}{|c|}{ Durée d'incubation (h) } \\
\hline & & \multicolumn{2}{|l|}{6} & \multicolumn{2}{|c|}{12} & \multicolumn{2}{|c|}{24} & \multicolumn{2}{|c|}{48} \\
\hline & & $\mathrm{FL}$ & $\mathrm{EM}$ & $\mathrm{FL}$ & EM & $\mathrm{FL}$ & EM & FL & EM \\
\hline Matière sèche & $\begin{array}{l}\text { P } \\
\text { A } \\
\text { ETR (S) }\end{array}$ & $\begin{array}{l}58,2 \\
60,1 \\
5,5\end{array}$ & $\begin{array}{r}52,3 \\
60,7 \\
5\end{array}$ & $\begin{array}{c}76,7 \\
73,2 \\
3,3\left(F^{+}, F\right.\end{array}$ & $\begin{array}{r}68,5 \\
72,0 \\
\times \mathrm{C}^{+1}\end{array}$ & $\begin{array}{l}90,6 \\
84,4 \\
2,31\end{array}$ & $\begin{array}{r}83,5 \\
81,1 \\
++1\end{array}$ & $\begin{array}{l}93,2 \\
87,7 \\
1,31 \mathrm{C}\end{array}$ & $\begin{array}{r}92,2 \\
88,2 \\
++1\end{array}$ \\
\hline Azote & $\begin{array}{l}\text { P } \\
\text { A } \\
\text { ETR (S) }\end{array}$ & $\begin{array}{l}50,7 \\
46,0 \\
6,0\end{array}$ & $\begin{array}{l}47,5 \\
44,1\end{array}$ & $\begin{array}{l}72,0 \\
64,1 \\
4,4 \text { ! }\end{array}$ & $\begin{array}{r}63,9 \\
61,1 \\
++1\end{array}$ & $\begin{array}{l}91,2 \\
84,4 \\
3,7(\end{array}$ & $\begin{array}{r}85,2 \\
76,2 \\
++1\end{array}$ & $\begin{array}{l}94,1 \\
91,3 \\
(2,3\end{array}$ & $\begin{array}{r}91,6 \\
90,3\end{array}$ \\
\hline Paroi (NDF) & $\begin{array}{l}\text { P } \\
\text { A } \\
\text { ETR (S) }\end{array}$ & $\begin{array}{l}17,6 \\
-0,0 \\
13,010\end{array}$ & $\begin{array}{r}11,4 \\
-5,7 \\
+1\end{array}$ & $\begin{array}{c}52,3 \\
28,6 \\
8,6\left(\mathrm{~F}^{++}\right.\end{array}$ & $\begin{array}{l}35,6 \\
15,2 \\
C^{++}\end{array}$ & $\begin{array}{c}78,8 \\
40,2 \\
4,5\left(\mathrm{~F}^{+}\right.\end{array}$ & $\begin{array}{l}66,8 \\
30,5 \\
\left.\mathrm{C}^{++}\right)\end{array}$ & $\begin{array}{l}87,0 \\
51,7 \\
4,3\left(\mathrm{~F}^{+}\right.\end{array}$ & $\begin{array}{l}84,0 \\
42,6 \\
\text { C) }\end{array}$ \\
\hline $\begin{array}{l}\text { Lignocellulose } \\
\text { (ADF) }\end{array}$ & $\begin{array}{l}\text { P } \\
\text { A } \\
\text { ETR (S) }\end{array}$ & $\begin{array}{l}18,1 \\
10,6 \\
10,0\end{array}$ & $\begin{array}{r}10,7 \\
4,9\end{array}$ & $\begin{array}{c}45,9 \\
25,4 \\
6,6\left(F^{++}\right.\end{array}$ & $\begin{array}{l}22,8 \\
12,1 \\
C^{++1}\end{array}$ & $\begin{array}{c}73,5 \\
30,0 \\
4,5\left(\mathrm{~F}^{+}\right.\end{array}$ & $\begin{array}{l}55,0 \\
21,1 \\
\mathrm{C}^{++}\end{array}$ & $\begin{array}{l}79,1 \\
31,8 \\
\quad 7,11 \mathrm{C}\end{array}$ & $\begin{array}{r}73,2 \\
33,4 \\
++1\end{array}$ \\
\hline $\begin{array}{l}\text { Matière sèche } \\
\text { soluble dans le } \\
\text { détergent neutre }\end{array}$ & $\begin{array}{l}\text { P } \\
\text { A } \\
\text { ETR (S) }\end{array}$ & $\begin{array}{l}80,4 \\
75,5 \\
2,6(\mathrm{~F} \times\end{array}$ & $\begin{array}{l}76,6 \\
77,7 \\
\left.C^{+}\right)\end{array}$ & $\begin{array}{l}91,2 \\
84,5 \\
1,9(\mathrm{~F} \times\end{array}$ & $\begin{array}{c}87,4 \\
86,2 \\
C^{++1}\end{array}$ & $\begin{array}{l}96,5 \\
95,4\end{array}$ & $\begin{array}{l}95,9 \\
93,7\end{array}$ & $\begin{array}{l}98,2 \\
97,9 \\
0,4\end{array}$ & $\begin{array}{r}98,4 \\
97,9\end{array}$ \\
\hline
\end{tabular}

(1) Sigles. $P=$ Aliment paroi ; $A=$ Aliment amidon; $E T R(S)=$ Ecart-type résiduel et signification des effets fourrage $(F)$, concentré $(C)$ ou interaction $(F \times C)$ aux niveaux $5 \%(+), 1 \%(++)$; $\mathrm{FL}=$ Régime de base foin de luzerne $; \mathrm{EM}=$ Régime de base ensilage de maïs.

Gueneau S., Bertrand D., 1984. Cahier des techniques de I'INRA, $\mathrm{n}^{\circ} 4,33-38$.

Lindberg J. E., 1981. Swedish J. agric. Res., 11, 159-169.

Sauvant D., 1980. p. 1-15. In CAAA. Matières premières à cellulose facilement digestible.

Weakley D. C., Stern M. D., Satter L. D., 1983. J. anim. Sci., 56, 493-507. 